\title{
EXPERIÊNCIAS DE TRABALHADORES NA EXTRAÇÃO DE PEDRAS GRANÍTICAS EM SANGÃO 1960 - 1990
}

\author{
João Henrique Zanelatto ${ }^{1}$ \\ Jhonata Goulart Serafim ${ }^{2}$
}

Resumo: A extração da pedra granítica foi, por várias décadas do século $X X$, uma das principais atividades econômicas do município de Sangão. Entre a década de 1960 e de 1990, uma quantidade significativa de trabalhadores experimentou duras condições de trabalho na exploração das pedreiras. Essa atividade apresentou várias especificidades nas relações de trabalho e o trabalho artesanal desenvolvido de forma autônoma marcou as singularidades dessa categoria de trabalhadores.

Palavras-chave: Experiência, trabalho artesanal.

Abstract: The extraction of the stone was for several decades of the century XX one of the main economic activities of the municipal district of Sangão. Among the years of 1960 up to 1990 a significant amount of workers experienced hard work conditions in the exploration of the quarries. That activity presented several specificities in the work relationships and the developed handmade work in an autonomous way marked the singularities of that category of workers.

Keywords: Experience, handmade work.

\section{INTRODUÇÃO}

Atualmente, no município de Sangão, observa-se que um pequeno número de trabalhadores tem, na extração da pedra granítica, a sua principal fonte de subsistência. Durante várias décadas, essa atividade consistiu em um fator de grande relevância na economia do município. Contudo, os trabalhadores desse setor encontram-se invisíveis na historiografia e também na documentação, uma vez que há uma escassez de fontes que tratam do desenvolvimento dessa atividade e das suas relações de trabalho.

\footnotetext{
${ }^{1}$ Doutor em história e professor do curso de História da Universidade do Extremo Sul Catarinense. Email:jhz@unesc.net

${ }^{2}$ Graduado em História pela Universidade do Extremo Sul Catarinense. E-mail: jhonatags@bol.com.br
} 
Por que esses trabalhadores encontram-se ainda invisíveis na historiografia? Responder a essa questão significa afirmar que grande parte da produção historiográfica sobre o Sul Catarinense, até o final da década de 1990, foi escrita na perspectiva do paradigma da história tradicional. Esse paradigma centrava seus escritos em uma história pautada nas elites administrativa, militar e religiosa e dava ênfase aos grandes feitos dos governantes, dos generais. Ou seja, era uma história vista de cima, elogiosa, elitista, descritiva e que se apresentava como a verdade ${ }^{3}$. Foi, somente na virada do século XX para o XXI, que começaram a aparecer trabalhos que divergiam do paradigma tradicional. Nesse contexto de renovação historiográfica do Sul Catarinense, é que apareceram estudos dando voz aos trabalhadores da região, em especial, aos mineiros ${ }^{4}$.

$\mathrm{Na}$ tentativa de dar visibilidade a esses trabalhadores, entende-se que é pertinente remontar, rapidamente, ao processo de constituição do município de Sangão. Esse pequeno município está localizado, no sul do estado de Santa Catarina, situado entre as cidades de Criciúma e Tubarão, uma região conhecida, tradicionalmente, pela economia baseada na agricultura, na extração do carvão e na cerâmica.

De acordo com a historiografia local, Sangão começou a ser ocupado, no final do século XIX. Inicialmente, recebeu o nome de "Rua do Fogo", pois era local de passagem de tropeiros que vinham do planalto Serrano com destino a Laguna e ali pernoitavam, faziam fogueiras para se protegerem do frio e de animais selvagens. Essa comunidade pertencia ao município de Jaguaruna e foi elevada, no ano de 1934, à categoria de distrito, vindo a conquistar, em 1992, a sua emancipação política e administrativa 5 .

Os poucos estudos encontrados sobre a história de Sangão constituem-se, basicamente, de monografias de conclusão de Curso e de uma obra sobre o município.

\footnotetext{
${ }^{3}$ BURKE, Peter (org.). A escrita da história: novas perspectivas. São Paulo: Editora da Universidade Estadual Paulista, 1992. O autor aponta para seis pontos de contraste entre a história tradicional e a nova história.

${ }^{4}$ VOLPATO, Teresinha Gascho. Vidas marcadas: trabalhadores do carvão. Tubarão: Unisul, 2001.; CAROLA, Carlos Renato. Dos subterrâneos da história: as trabalhadoras das minas de carvão de Santa Catarina (1937-1964). Florianópolis: Ed. da UFSC, 2002. e ZANELATTO, João Henrique. Homens do Barro: Experiências dos trabalhadores da cerâmica vermelha (olarias) em Morro da Fumaça (1970-1990). Florianópolis: Universidade Federal de Santa Cataria, (Dissertação de Mestrado em História), 1998.

${ }^{5} \mathrm{O}$ processo das formações social, política e econômica de Sangão pode ser encontrado nos estudos de: BOTEGA, Andrade. História do Município de Sangão. Tubarão: UNISUL, (Monografia, trabalho de conclusão de curso), 1996. e VIEIRA, Edmo Henrique. Inventário e Reconhecimento do Patrimônio Histórico e Arquitetônico da Cidade de Sangão - SC. Tubarão: UNISUL, (Monografia, trabalho de conclusão de curso), 2007.
} 
Ao analisar esses estudos, foi possível encontrar pequenos trechos que se referiam aos trabalhadores da pedra.

É grande a presença de pedra granítica nessa região. Existem no município cerca de 485 cortadores de pedras. Esta fonte de renda é baseada no corte de granito, que ocupa uma expressiva parcela da população. Normalmente quem trabalha nessa atividade é a própria família, sendo o trabalho de corte totalmente artesanal. ${ }^{6}$

Observa-se, na citação, a importância social, econômica e cultural desse trabalho e dos seus trabalhadores no município. Havia um número significativo de trabalhadores desenvolvendo essa atividade, se comparado ao pequeno número de habitantes da localidade. Na década de 1980, segundo os dados do IBGE, havia 3.704 habitantes, em 1991, 6.771 habitantes e, atualmente, há um total de $10 \mathrm{mil}$ habitantes ${ }^{7}$.

A importância econômica e social do trabalho e dos trabalhadores da pedreira, em Sangão, fica evidenciada no adesivo de campanha pela emancipação utilizado em 1991 e no brasão do município. Tanto no adesivo como no brasão ${ }^{8}$ foram destacadas as três principais atividades econômicas do município: a agricultura, a extração de pedras e a cerâmica.

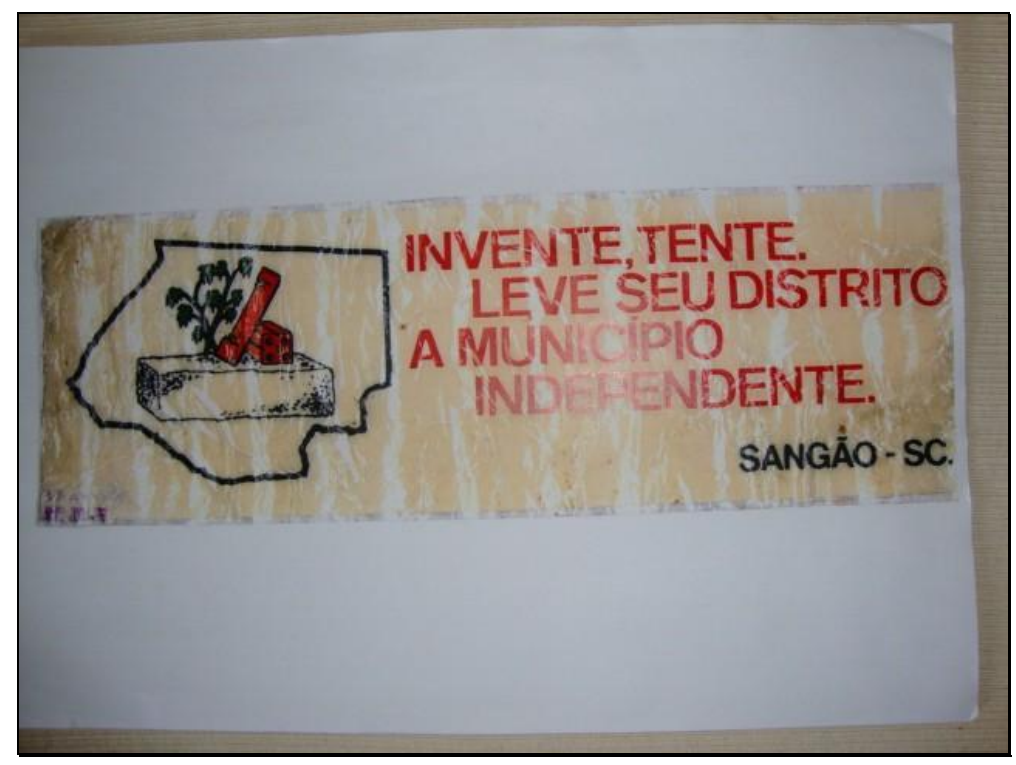

Fig. 1. Adesivo do município. Foto do autor.

\footnotetext{
${ }^{6}$ BOTEGA, Andrade. História do... op. cit,. p. 31.

${ }^{7}$ Dados do IBGE e da prefeitura municipal de Sangão.

${ }^{8}$ Sobre o brasão, cf. prefeitura municipal de Sangão.
} 
Observa-se, no adesivo, ao lado da frase do slogan da emancipação, o mapa do novo município, e, nele, os quatro principais produtos da economia do município: a pedra, destacada com muita ênfase, a mandioca, o tijolo e a telha. Esses elementos são indícios da relevância socioeconômica das pedreiras e de seus trabalhadores, em Sangão, em especial, entre as décadas de 1960 e de 1990.

Este artigo tem por objetivo perceber o processo de constituição dos trabalhadores da extração de pedra (categoria de trabalhadores autônomos), que desenvolveram um trabalho artesanal e produziram especificidades nas suas relações de trabalho. Além disso, pretende-se identificar como esses trabalhadores adquiriam a pedra (posse, compra, arrendamento), quais os produtos que eram derivados da pedra, reconhecer como era desenvolvido esse trabalho (artesanal) e compreender o processo de comercialização da pedra (quem comprava, para onde era vendida, como eram definidos os preços e o mercado consumidor).

Na tentativa de explicar como os trabalhadores da pedra foram se constituindo, buscou-se fazer uma abordagem cultural da história. A noção de experiência de Thompson $^{9}$ foi de fundamental importância para esse estudo. A experiência é entendida como o processo de constituição do social, que se configura, não somente, nos sistemas econômicos, nos regimes políticos institucionais, como também na maneira como os sujeitos sociais elaboram e reelaboram seus modos de viver. As obras de Thompson permitem perceber a constituição da classe operária, em um processo de formação e de luta que se manifesta em todos os aspectos da vida. A constituição dos trabalhadores da pedra, tal como observou Thompson "é um fato tanto da história política e cultural quanto da economia"10.

As experiências dos trabalhadores da pedra foram buscadas em suas memórias. Ao evocar a memória, é preciso entender que é socialmente construída, pois a recordação faz com que se aproprie de um passado produzido e mantido socialmente. As narrativas expressam-se através de pontos de vistas próprios, buscados no ontem e reinterpretados hoje, pois, como afirma Ecléa Bosi, "na maior parte das vezes, lembrar não é reviver, mas refazer, reconstruir, repensar com imagens e idéias de hoje as experiências do passado". ${ }^{11}$

\footnotetext{
${ }^{9}$ Sobre a noção de experiência, cf. THOMPSON, Edward Palmer. A miséria da teoria: ou um planetário de erros. Rio de Janeiro: Zahar, 1981. e Idem. A formação da classe operária inglesa. 3 Volumes. Rio de Janeiro: Paz e Terra, 1987.

${ }^{10}$ Ibidem, vol. II, p. 17.

${ }^{11}$ BOSI, Ecléa. Memória e sociedade: lembranças de velhos. São Paulo: Edusp, 1987, p. 17.
} 
Para Halbwachs ${ }^{12}$, a memória do individuo está relacionada à família, à classe social a que pertence, à escola, à igreja, à profissão, enfim, é constituída pelos grupos sociais, tem uma dimensão coletiva, espontânea, múltipla e é guardiã do passado. Contudo, o autor explica que a memória não deixa de ter também um componente individual.

Ressalta-se que é preciso ter clareza que os discursos da memória não são desprovidos de riscos: são plurais, maleáveis instáveis, imprevistos, descontínuos, entrelaçam acontecimentos diversos e sofrem influência dos meios de transmissão e de comunicação ${ }^{13}$. Cabe ao historiador fazer a leitura, nas entrelinhas, desses discursos, rever interpretações e refinar o que se apresentava como a verdade.

\section{SOBRE A CONSTITUIÇÃO DOS TRABALHADORES DA PEDRA}

O distrito de Sangão, no final dos anos de 1950 e no início da década de 1960, tinha, na agricultura, a principal alternativa de subsistência dos seus habitantes. Destacavam-se a culturas da farinha de mandioca, do milho, do arroz e do fumo ${ }^{14}$. No entanto, esse modo de subsistência dependia de uma série de fatores que influenciavam, diretamente, na produção agrícola, como, por exemplo, o enfraquecimento das terras, a mecanização da agricultura e a subdivisão da propriedade agrícola por herança ${ }^{15}$. Pode-se inferir que os elementos descritos acima foram determinantes na permanência ou na tentativa do indivíduo a se aventurar em outra forma de conseguir seu sustento: "A agricultura, na época, meio... A gente sozinho era ruim, de trabalhar. Pouca gente. Então agente foi trabalhar. Saí da família casô, então foi cortar pedra. Emprego não era muito bom na época. Trabalhar na agricultura sozinho, fazer lavoura, meio difícil. ${ }^{16} \mathrm{Em}$ sua narrativa, o senhor João Olindino explica o momento e o motivo que o levaram a trabalhar como graniteiro. Ele destaca que, para o trabalho com a agricultura, era necessário um número, relativamente, grande de trabalhadores, sendo uma atividade quase que, predominantemente, familiar. Assim, após o casamento, os indícios levam a crer que, não conseguindo um trabalho formal e sendo mais difícil empreender sozinho o

\footnotetext{
12 Sobre a discussão da memória, cf. HALBWACHS, Maurice. A memória coletiva. São Paulo: Vértice/Editora Revista dos Tribunais, 1990.

${ }^{13}$ As memórias são influenciadas pela organização social, pela transmissão e pelos diferentes meios de comunicação empregados. Cf, BURKE, Peter. Variedades da história cultural. Rio de Janeiro: Civilização brasileira, 2000, p. 73.

${ }^{14}$ WASEM, Nysio Felippe. Custódia Borges Brasil e história de Sangão. Criciúma: JC Dias, 2008, p. 79.

${ }^{15}$ SINGER, Paul. A formação da classe operária. 6. ed. São Paulo: Atual, 1988, pp. 62-63.

${ }^{16}$ João Olindino Tomaz. 57 anos. Entrevista concedida ao autor em 24/09/2008. (Preservada a linguagem do entrevistado).
} 
trabalho agrícola, o senhor João Olindino foi obrigado a trabalhar nas pedreiras. Essa condição foi experimentada por muitos trabalhadores do distrito de Sangão que migraram da agricultura para o trabalho nas pedreiras. Cabe destacar que essa atividade era também desenvolvida, na região dos municípios de Treze de Maio e de Tubarão.

Outros trabalhadores, no entanto, experimentaram períodos de trabalho com a agricultura e com a extração de pedra. $O$ trabalho com a pedra era realizado entre 0 semear e a colheita das lavouras e, sendo uma atividade mais constante (devido às intempéries do tempo que atrapalhavam o desenvolver da lavoura), muitos trabalhadores acabaram trabalhando apenas com a extração de pedra. Além das dificuldades com a agricultura, forma de produção predominante da região de Sangão, durante os anos 60 e nas décadas seguintes, foi possível encontrar outros fatores que também contribuíram para o ingresso de muitos trabalhadores no corte de pedras. A narrativa do senhor Sebastião evidencia o exposto: "Além de ser um serviço por minha conta mesmo, né, e não dependia de nada, enquanto que pra trabalhar assim de empregado, ai não existia serviço, era muito difícil. Era difícil na época se conseguir um emprego" ${ }^{17}$. Portanto, duas razões foram destacadas pelo senhor Sebastião para que fosse trabalhar com o corte de pedras. A primeira era o trabalho autônomo, que foi muito enfatizado. Era "um serviço por minha conta, né, e não dependia de nada".

Infere-se que, para o senhor Sebastião, o trabalho autônomo, nas pedreiras, deixaria-o livre do controle exercido dentro das fábricas. Entretanto, quando é destacada a segunda razão para trabalhar nas pedreiras, explica que não havia opções de trabalho, ou seja, trabalho formal nas décadas de 60 e de 70 . Isso leva a crer que o trabalho, nas pedreiras, pareceu ser muito mais uma imposição do que uma opção. Assim, frente a uma agricultura de garantias duvidosas e à falta de emprego formal, um número significativo de trabalhadores encontrou, nas pedreiras, uma maneira de garantir a sua sobrevivência.

Além dos motivos citados acima quais outras explicações podem ser dadas para o crescimento da atividade, nas pedreiras, em Sangão? Por que um número significativo de trabalhadores deslocou-se para essa atividade? 0 que provocou o aumento do consumo dos derivados da pedra?

O grande crescimento econômico ocorrido, na região carbonífera, a partir da década de 1940, em especial, no município de Criciúma foi fundamental para a ampliação da atividade nas pedreiras. O crescimento da exploração do carvão, com a

\footnotetext{
${ }^{17}$ Sebastião Cândido Fernandes. 71 anos. Entrevista concedida ao autor em 10/12/2008. (Preservada a linguagem do entrevistado).
} 
segunda guerra mundial, provocou um grande fluxo migratório para Criciúma. Basta dizer que a população do município praticamente dobrou entre 1940 e 1950. Aliado à exploração do carvão, no final dos anos 50, despontava também o setor cerâmico, transformando Criciúma em cidade polo na região Sul ${ }^{18}$. Esse crescimento exigia uma infraestrutura para atender o cenário urbano uma vez que a construção civil crescia acentuadamente. Foi, nesse contexto, que materiais como "pedra de alicerce" para casas e prédios, "paralelepípedos" e "meio-fio" para calçamento de ruas ganharam mercado e contribuíram, assim, para o grande crescimento da atividade extrativista nas pedreiras.

Nas pedreiras, os trabalhadores tinham maior liberdade tanto no momento de produzir quanto na hora de vender os produtos. Além disso, também tinham liberdade para organizar seu próprio horário de trabalho. Nesse ponto, é importante destacar que, como esses trabalhadores eram autônomos, poderiam trabalhar por um período diário de horas maior do que o "normal" para conseguirem um rendimento mais alto, labutando, inclusive, aos sábados e aos domingos. Além disso, o trabalho, nas pedreiras, levou à exploração da mão-de-obra infantil, haja vista que muitos pais levavam as crianças, desde cedo, para trabalhar junto a eles.

\begin{abstract}
Não tinha idade, é que pra trabalhar na pedra, tinha pais que botava os filhos junto com eles aprendendo já com 10 anos. Eu, por exemplo, botei o meu com 13 anos, né, porque muito novo, então com 13 anos já tem mais força pra começar, ai começando novo dá bom, mas se começar velho não aprende. É! A pedra tem disso! É coisa que precisa continuação, é um serviço que não é como agente diz, a gente escreve. Não! É a prática. O tempo. A continuação. ${ }^{19}$
\end{abstract}

Pode-se perceber, através do depoimento do senhor Sebastião, que, nessa profissão de autônomo, o trabalho infantil era "comum" e justificado como "necessário" para que o futuro trabalhador pudesse adquirir experiência e fosse, assim, um bom profissional. Era preciso um longo tempo de aprendizagem, pois "começando novo dá bom, mas se começar velho não aprende".

Em relação às vestimentas usadas para trabalhar, não havia um uniforme a ser usado por todos os graniteiros. Cada trabalhador usava a vestimenta e o calçado que Ihe fosse mais adequado e confortável para as várias ocasiões do processo. Em dias

\footnotetext{
${ }^{18}$ Sobre o crescimento do município de Criciúma e da região com a exploração do carvão, cf. GOULARTI FILHO, Alcides. (org). Memória e cultura do carvão em Santa Catarina. Florianópolis: Cidade Futura, 2004.; SANTOS, Mauricio Aurélio dos. Crescimento e crise na região Sul de Santa Catarina. Florianópolis: UFSC, 1995.; VOLPATO, Terezinha Gascho. A pirita humana: os mineiros de Criciúma. Florianópolis: Ed. da UFSC/ALESC, 1994. e TEIXEIRA, José Paulo. Os donos da cidade. Florianópolis: Insular, 1996.

${ }^{19}$ Sebastião Cândido Fernandes. 71 anos, dc. cit.
} 
muito quentes como, no verão, alguns usavam camisa, calção e sandálias; já nos dias frios, as roupas eram mais pesadas. Outros preferiam trabalhar sempre usando roupas mais pesadas com o objetivo de proteger o corpo contra os pedregulhos provenientes do constante choque mecânico efetuado entre a marreta ou a maceta no ponteiro contra a pedra.

É importante destacar que, se por um lado, as condições de trabalho com a pedra eram, extremamente, duras, tendo em vista que todas as atividades exigiam o uso de força extrema, por outro, havia uma certa "vantagem" na condição de trabalhador autônomo, pois, em dias muito quentes, no verão, por exemplo, principalmente, próximo ao meio dia ou no início da tarde, quando o sol estava ainda mais quente, os trabalhadores paravam de trabalhar. Essa parada era feita sem dar nenhuma satisfação a qualquer encarregado ou patrão.

O trabalho no corte de pedras graníticas dependia de uma série de instrumentos (ferramentas) de trabalho para vários tipos de produtos e para as diversas etapas do processo de transformação de uma pedra granítica de grandes dimensões em muitos derivados. Deve-se destacar que os nomes dos instrumentos de trabalho podiam variar de acordo com cada trabalhador. Os principais e os mais importantes instrumentos de trabalho foram descritos pelo senhor José Olindino: "era o martelo e... ponteiro, ponchote, escopo, broca, raia e explosivo pra arrebentar a pedra, estopim e pólvora feito por nós... Tinham malho também tinha marreta... Nós usava a marreta grande pra bater no ponchote e a marreta menor que pra escalhar, escalhar a pedra, pra tirar aquele bico" 20 .

Além desses instrumentos, que eram os principais, outras ferramentas foram destacadas pelo senhor José Olindino: alavanca, estrangulim, espaceta, recaladeira, ataque e gato. Havia também outras ferramentas que eram utilizadas antes do corte das pedras graníticas, como a picareta e a pá, que eram usados para remover a terra ao redor da pedra a ser cortada. Os instrumentos eram, em sua maioria, de ferro e necessitavam ser "apontados", diariamente ou semanalmente, em ferrarias ou pelos próprios graniteiros em suas residências ou no local de trabalho.

\footnotetext{
${ }^{20}$ José Olindino Tomaz. 60 anos. Entrevista concedida ao autor em 20/09/2008. (Preservada a linguagem do entrevistado).
} 


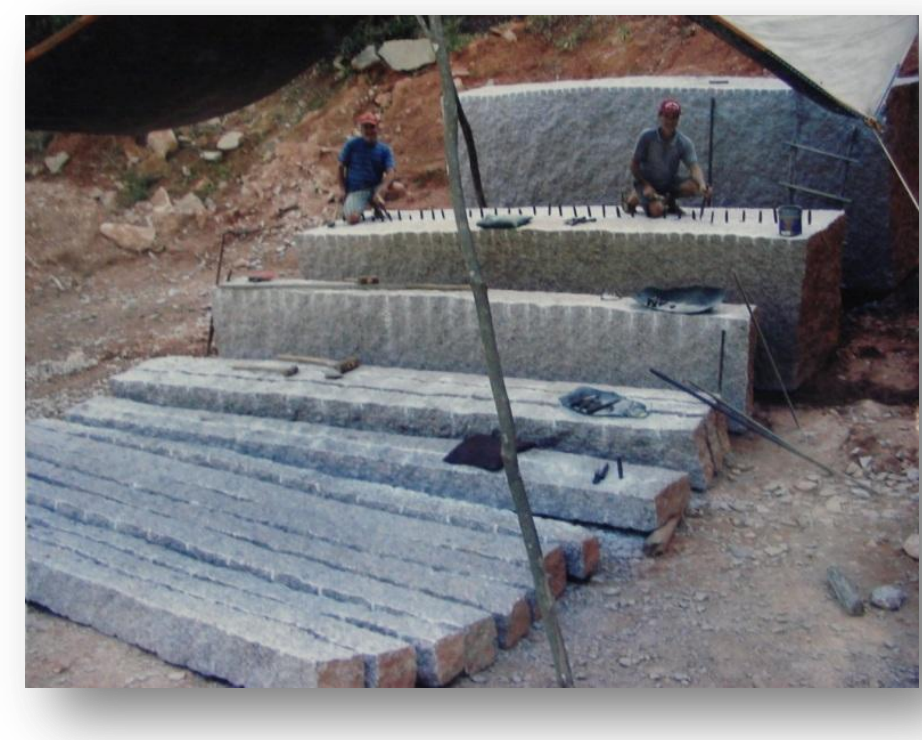

Trabalhadores utilizando suas ferramentas no "corte" das pedras ${ }^{21}$

Além das várias ferramentas, o trabalho com a pedra exigia dos trabalhadores muita cautela no momento de se começar a cortar uma pedra, pois há várias técnicas e uma linguagem específica desse trabalho, como relata o senhor Manoel Antônio Eduardo, ao falar sobre os tipos de cortes da pedra:

Tem o sêda de cabeça que acompanha o sol e o trincante de cabeça, né, em cima da pedra. Depois tem o levante, que é do lado da pedra. Então tem o lavante sêda que é o melhor, e tem o levante trincante que é o pior, também tem a o corte de botornera. De acordo de como a pedra tá no lugar, a gente usa um desses corte. [...] Tem a grana fina e a grana grossa: a fina é mais bonita porque é lisinha, mas pra construção é melhor a grana grossa, porque gruda mais no cimento. ${ }^{22}$

\footnotetext{
${ }^{21}$ Arquivo privado, arquivo do autor. Utilizou-se a expressão "cortar as pedras", pois era a utilizada pelos trabalhadores.

${ }_{22}$ Manoel Antonio Eduardo. 67 anos. Entrevista concedida ao autor em 12/02/2009. (Preservada a linguagem do entrevistado).
} 

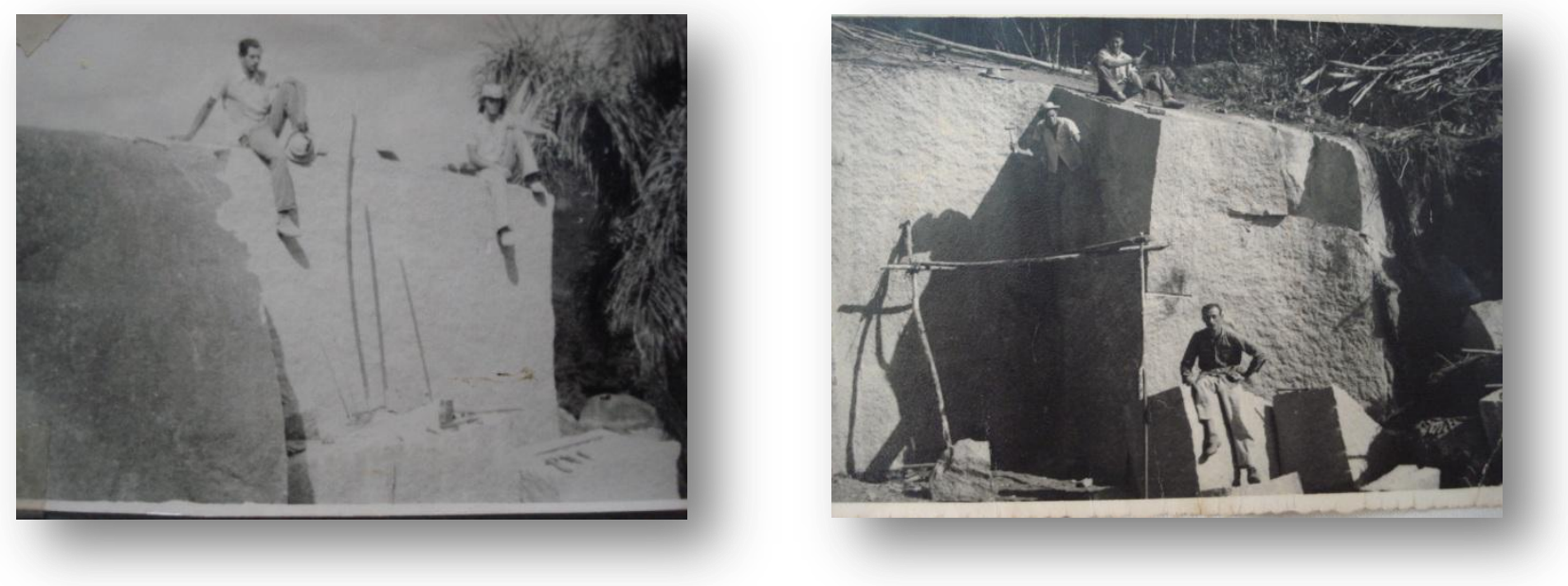

Trabalhadores na pedreira da década de $1970^{23}$

Os relatos do senhor José Olindino e do senhor Manoel Antônio Eduardo, bem como as imagens, contribuem para demonstrar que a história não é movida apenas pelo econômico, mas é também movida pela cultura. É dessa forma que se percebe a relevância do conceito de experiência, pois, através dele, é possível analisar e observar a importância da cultura na história, cultura que se expressa através de normas, regras, comportamentos, condutas, valores e linguagens ${ }^{24}$. Por meio das narrativas, fica evidente que os trabalhadores da pedra criaram e recriaram valores, comportamentos e linguagens próprias, que eram usados no cotidiano.

Destacam-se ainda outros aspectos na analise das fotografias e do relato dos trabalhadores. A fotografia mostra os trabalhadores no seu local de trabalho. É possível observar dois momentos. Enquanto as duas últimas fotografias revelam as pedreiras ainda em um estágio bruto uma vez que os trabalhadores estão cortando e recortando a pedra, a primeira fotografia destaca o produto final, um tipo de produto (esteio). Por sua vez, os relatos dos trabalhadores, como já foram expostos, apontam para os tipos de ferramentas e as técnicas no corte das pedras. O trabalho nas pedreiras dependia de um saber, do domínio de um conhecimento empírico. Tal conhecimento ia desde o domínio sobre a confecção das ferramentas até sobre a melhor forma para o corte das pedras, pois nenhuma atividade era mecanizada e todo trabalho dependia do esforço individual ou coletivo dos trabalhadores. Uma maior produção implicava em boas pedreiras e em mais trabalho, não apenas em horas, mas, também, em muito esforço físico.

\footnotetext{
${ }^{23}$ Arquivo privado, as fotografias são do arquivo pessoal do senhor José Olindino e do senhor João Zanelatto.

${ }^{24}$ Sobre o conceito de cultura, cf. THOMPSON, Edward Palmer. A formação... op. cit., 3 Vols.,
} 


\section{DA COMPRA DAS PEDREIRAS À VENDA DOS PRODUTOS}

O senhor João Zanelatto se lembra da compra das pedreiras: "Comprava dos agricultores ou arrendava, a maioria arrendava, eu gostava de comprar porque ficava mais livre... Os agricultores eram os proprietários do terreno. 0 arrendamento era 10 por cento sobre a produção" ${ }^{25}$. Pode-se inferir, da fala do senhor João Zanelatto, que as pedreiras eram adquiridas de duas maneiras: por arrendamento ou por compra. No caso do arrendamento, o relato sugere que havia um consenso no valor (10 por cento sobre a produção) que era cobrado pelo arrendamento. Em relação à compra da pedreira, o senhor João Zanelatto ainda explica que ela podia ser tanto à vista ou à prestação, tudo registrado em contrato firmado entre o comprador (graniteiro) e o vendedor. $\mathrm{O}$ contrato de compra da pedreira era firmado e registrado em cartório. $\mathrm{O}$ relato do senhor João Zanelatto também sugere que o trabalho, nas pedreiras, dava uma grande margem de autonomia para o graniteiro desenvolver seu trabalho, principalmente, para os que compravam a pedreira. $O$ entrevistado ainda deixa explícito que as pedreiras eram arrendadas ou compradas dos agricultores de Sangão.

Os produtos derivados da pedra eram os seguintes: paralelepípedo (popularmente, denominado de macaco), que era utilizado para calçamento de ruas; meio-fio utilizado em vias públicas, principalmente, nas cidades; esteio, que funcionava como uma viga para sustentação de galpões; moeirão ou palanque de cerca, que era utilizado para sustentar cercas de arame. Contudo, o mais produzido, durante todo o período estudado, foi a pedra de obra ou a pedra de alicerce, usada pela construção civil no alicerce de várias obras: casas, edifícios, muros. A venda desses produtos era realizada através das seguintes medidas: ou em metros corridos ou por peças. Alguns vendiam toda a sua produção apenas em metros corridos. As medidas dos produtos podiam variar de acordo com os pedidos: o moeirão, o esteio, o meio-fio e a pedra de alicerce eram comercializados por metro corrido e sua largura e sua espessura variaram de acordo com o tempo. Nas décadas de 1960 e de 1970, por exemplo, as pedras para alicerce eram vendidas por metro corrido e sua largura e sua espessura eram de quarenta centímetros por quarenta centímetros ou quarenta por quarenta, como diziam os trabalhadores. Já no final da década de 1970 e no início dos anos 80, a largura e a espessura diminuíram gradativamente, caindo para trinta

\footnotetext{
${ }^{25}$ João Zanelatto. 71 anos. Entrevista concedida ao autor em 27/09/2008. (Preservada a linguagem do entrevistado).
} 
centímetros e, posteriormente, vinte centímetros. O paralelepípedo era o único produto a ser comercializado em unidade.

Sobre a comercialização dos produtos derivados da pedra, mais uma vez, evoca-se memória do senhor João Zanelatto.

É que não existia assim cooperativa, cada um vendia. Existia vários compradores. No caso daquela época o paralelepípedo era mais pra prefeitura, já era direto. Hoje não, hoje sempre tem os intermediários que compra, acredito sim eram vários compradores, hoje aqui... o Zezinho Aranquã, tem outros aí, cada um puxava. Bastião da Marina ali. Aquela época também era assim, só que eram outros. Não existia assim uma cooperativa que vendesse que... Cada um vendia pra quem achava melhor. ${ }^{26}$

Portanto, não havia um comprador definido, mas vários vinham com seus caminhões e os carregavam nas pedreiras em que o preço e a qualidade fossem melhores. Muitos dos que compravam as pedras dos graniteiros eram intermediários que revendiam os derivados para as lojas que comercializavam materiais de construção ou para particulares. O principal destino para os produtos provenientes da extração da pedra granítica era Criciúma:

A comercialização, os caminhão de Criciúma vinham pra cá. Os comprador eram de Criciúma, posso dar até o nome de alguém... Vendramino, Valério, Gentil Fausto, Dário Manhante, aquela vez era pouco, depois veio João Dagostin, Debrando Zanatta. [...] Nosso material saía mais era pra Criciúma, depois começou praia do Rincão, mas sempre pra outro lado, pra Tubarão não saía, porque pra Tubarão sempre tinha gente que cortava lá né, então eles supriam lá, tinha o Delírio lá da britadeira. ${ }^{27}$

Além de Criciúma, as pedras cortadas em Sangão eram também comercializadas em outros municípios: Balneário Rincão (pertencente ao município de Içara), Morro da Fumaça, Urussanga, Nova Veneza e outros. Como não havia cooperativa e cada um trabalhava para si, o preço não era constante e variava de acordo com a concorrência. Como já foi exposto, os vários derivados da pedra eram vendidos, principalmente, para as lojas de material de construção de Criciúma, como, por exemplo, as lojas Rafael Zanete, Colombo, Ortolan, Manenti, Zanatta, João de Barro, dentre outras; para as prefeituras municipais, em especial, meio-fio e paralelepípedo para pavimentação de ruas e também para particulares.

\footnotetext{
${ }^{26}$ João Zanelatto. 71 anos, doc. cit.

${ }^{27}$ Vaterlo de Bona Sartor. 67 anos. Entrevista Concedida ao autor em 27/09/2008. (Preservada a linguagem do entrevistado).
} 
No que tange à definição dos preços dos produtos, não havia uma regularidade e cada trabalhador fazia o seu preço. Este poderia variar por motivos diversos: pela urgência do graniteiro em vender o material, pela qualidade do derivado, mas, principalmente, pela acessibilidade do caminhão em chegar às pedreiras para carregar o material. Na região central do município, em que o acesso a BR-101 era próximo e as estradas eram boas, o preço era maior. Todavia, em lugares de mais difícil acesso (planaltos acentuados e estradas ruins), o preço era mais baixo para atrair os compradores. O pagamento, de maneira geral, era feito à vista (em espécie ou em cheque), após o carregamento do caminhão. Tal processo acontecia, semanalmente, pois era o tempo que, em média, os trabalhadores levavam para produzir um caminhão de pedra. Essa produção dependia das condições das pedreiras ou do desempenho do trabalhador. Havia trabalhadores que vendiam seus produtos apenas para uma loja de material de construção (tinha um freguês) e recebia o pagamento no final do mês.

\title{
SINDICATO E SAÚDE: TENTATIVAS INFRUTíFERAS DE ORGANIZAÇÃO DOS GRANITEIROS
}

\begin{abstract}
Foi tentado, foi tentado, mas fazer o que? Foi tentado, mas não deu. Porque o povo não se uniu, só se reuniam, mas não se uniu. Porque sempre tem aquele, né, que não que ficar submisso a alguém, ele que fazer o preço dele, vende como quer. Foi tentado fazer um sindicato, uma associação pra manter um preço melhor. Então, subir conforme precisasse, conforme a situação, pra manter o preço, fizeram bastante reunião. É que quando o preço ficava bem ruim, ficava mau, então se reuniam pra aumentar, aquela vez tinha muita inflação, então botava um preço, mas nunca ia aquele preço que se botava, depois vinha um pouco pra traz, por causa da necessidade. Mas sempre melhorava, dava melhora. ${ }^{28}$
\end{abstract}

Na fala do senhor Vaterlo, observa-se que os trabalhadores da pedra tentaram, em várias oportunidades, formar uma associação ou um sindicato. Essas tentativas acabaram sendo infrutíferas. Eles não conseguiram nem organizar um sindicato e nem mesmo uma associação: "foi tentado, foi tentado, mas fazer o que? Foi tentado, mas não deu." E por que não conseguiram se organizar? A explicação do senhor Vaterlo leva a crer que a condição de trabalhadores autônomos foi um grande empecilho para organização da categoria. Conforme afirmou o senhor Vaterlo, "o povo não se uniu, só se reuniam, mas não se uniu. Porque sempre tem aquele, né, que não quer ficar

\footnotetext{
${ }^{28}$ Ibidem.
} 
submisso a alguém ele quer fazer o preço dele vende como quer." Pode-se inferir também, na fala do senhor Vaterlo, que as reuniões dos trabalhadores da pedra ocorreram com mais frequência na década de 1980, período em que o país vivenciou altas taxas de inflação.

Outro aspecto relevante para se destacar foi que esses trabalhadores, mesmo não conseguindo criar uma associação ou um sindicato, conseguiram, nas suas reuniões, ainda que por curtos períodos, aumentar o preço do material produzido. Era, nas épocas de preços, extremamente, baixos, que os trabalhadores se reuniam e "então botava um preço, mas nunca ia aquele preço que se botava, depois vinha um pouco pra traz, por causa da necessidade. Mas sempre melhorava, dava melhora". Nessas reuniões, estabeleciam um preço único e, depois, acabavam cedendo, diminuindo um pouco do valor tabelado, inicialmente. Mas, ao que tudo indica, havia uma melhora considerável nos valores do produto. Assim, fica evidenciado que essas reuniões se constituíram no espaço máximo de organização dos trabalhadores da pedra $^{29}$.

Como foi observado anteriormente, a condição de trabalhador autônomo no corte de pedras apresentava algumas "vantagens". Todavia, esse trabalho autônomo também tinha várias desvantagens, principalmente, com relação à saúde dos trabalhadores. Como era uma atividade informal, ou seja, os trabalhadores não recebiam qualquer assistência do Estado, em caso de enfermidades, eram obrigados a custear todas as despesas. Os graniteiros também não tinham direitos a outros benefícios, como as férias e o 13으 salário. Alguns graniteiros pagavam INSS para conseguir aposentadoria por tempo de contribuição, como é o caso do senhor João Zanelatto, de 71 anos, aposentado por essa instituição. O senhor João era obrigado a pagar alvará, na prefeitura, para ser reconhecido como trabalhador pelo INSS. Eram poucos os que pagavam o INSS. A maioria trabalhava sem ter nenhum direito trabalhista.

Além dos direitos trabalhistas, que a maioria dos graniteiros não possuía, estes também trabalhavam sem qualquer proteção física, tendo apenas chapéus ou bonés para se protegerem do sol. A narrativa do senhor José Olindino aponta para o trabalho com a pedra e as condições de saúde:

\footnotetext{
${ }^{29}$ O final da década de 1970 e a década de 1980 foram marcados por grandes mobilizações dos trabalhadores brasileiros. Nesse período, foram criados associações e sindicatos. Os movimentos sociais estavam em plena efervescência e faziam as mais variadas reivindicações. Sobre esse assunto, cf. BOITO, Júnior. O sindicalismo brasileiro nos anos 80. Rio de Janeiro: Paz e Terra, 1991. e SADER, Eder. Quando novos personagens entraram em cena: experiências, falas dos trabalhadores da grande São Paulo 1970-1980. Rio de Janeiro: Paz e Terra, 1988.
} 
Até que concordo por causa da poeira, tem muita poeira, a gente quando trabalha na pedreira a gente vive com a venda cheia de poeira da pedra, e poeira de pedra é um concreto: tanto que o braço da gente, a gente trabalha com a mão direita no ponteiro né, o pó bate aqui; a gente lavava, lavava, lavava, tá limpo, depois secava, ficava branquinho de novo... E as narina da gente, aquilo gruda cara, gruda, aquilo é um concreto. Acho aquilo vai ao pulmão e nunca mais sai. ${ }^{30}$

A principal queixa dos trabalhadores da pedra sobre o serviço era o pó da pedra, pois, como esse trabalho não tinha qualquer regulamentação do Estado, por não ser reconhecido como profissão, também não havia regulamentação para o uso de vestimentas adequadas ao trabalho. As vestimentas eram escolhidas pelos próprios trabalhadores que, na maioria das vezes, não tinham noção dos perigos que a profissão impunha. Entretanto, quando questionado se o trabalho com a pedra seria ou não prejudicial à saúde, percebem-se algumas divergências de opinião. O senhor Amauri Vicente, que começou a trabalhar cortando pedra, e, depois, tornou-se "puxador", comprando os produtos dos graniteiros e os revendendo, narrou o trabalho nas pedreiras e sua relação com a saúde da seguinte maneira:

Eu acho que não, porque a pedra a gente trabalha ao ar livre, então tem um pouco de pó, mas o pó ele consegue sair, ele não fica. Bem, dizem que o pó é perigoso, mas é uma coisa que se fosse fechado, mas é aberto. Tem o pó, mas nem comparação como se fosse dentro de uma mina, ou dentro de uma fundição ${ }^{31}$.

Além do problema com o pó e da grande quantidade de força que o graniteiro tinha de empregar ao cortar os blocos, também aconteceram acidentes com explosivos e com os deslocamentos dos blocos de pedras. Os riscos com a saúde, a falta de direitos trabalhistas, bem como o processo de decadência da exploração das pedreiras, no município de Sangão (em especial, na década de 1990), foram muito bem narrados pelo senhor João Everaldo Fernandes:

Eu acho que não, porque a pedra a gente trabalha ao ar livre, então tem um pouco de pó, mas o pó ele consegue sair, ele não fica. Bem, dizem que o pó é perigoso, mas é uma coisa que se fosse fechado, mas é aberto. Tem o pó, mas nem comparação como se fosse dentro de uma mina, ou dentro de uma fundição. ${ }^{32}$

\footnotetext{
${ }^{30}$ José Olindino Tomaz. 60 anos, doc. cit, cf. nota 20 deste artigo.

${ }^{31}$ Amauri Vicente. 45 anos. Entrevista concedida ao autor em 15/01/2009. (Preservada a linguagem do entrevistado).

32 João Everaldo Fernandes. 47 anos. Entrevista concedida ao autor em 10/12/2008 (preservado linguagem do entrevistado).
} 
A fala do senhor João aponta para um impulso da indústria do cimento, que estabeleceu uma concorrência muito forte com os trabalhadores da pedra. Os vários produtos derivados da pedra começaram a ser produzidos com o cimento. Além disso, naquele contexto, Sangão se emancipou de Jaguaruna. Concomitante a esse processo político, ocorria uma grande mudança econômica. Foi o salto, no município, do setor cerâmico e da indústria metal mecânica, que seduziram jovens e adultos a trabalhar com salários fixos e com carteira assinada, garantindo também os demais serviços de um trabalhador formal. Dessa maneira, da década de 1990 em diante, foi observada uma redução significativa do número de trabalhadores das pedreiras no município de Sangão. Essa redução, contudo, não diminui a contribuição desses personagens na construção da história da cidade. Nesse sentido, procurou-se, aqui, dar visibilidade a essa categoria de trabalhadores, visibilidade esta que não foi evidenciada na historiografia e na documentação oficial. A difícil tarefa de reconstituir parte da história desses trabalhadores, que não se encontram nos documentos escritos, só foi possível através de suas memórias, pois, como sugere Janotti, a memória "rompe com os silêncios provenientes do quotidiano, do fazer anônimo, revelando acontecimentos, experiências e mentalidade que não se encontram nos documentos escritos e nas versões oficiais" ${ }^{33}$.

33 JANOTTI, Maria L. M. Refletindo sobre a história oral: procedimentos e possibilidades. In: (Re)Introduzindo História Oral no Brasil. São Paulo: Xamã, 1996, p. 60. 